(6) OPEN ACCESS

${ }^{1}$ Centre for Healthcare Ethics (CHE), Karolinska Institutet, Stockholm, Sweden

${ }^{2}$ Department of Law, Stockholm University, Stockholm, Sweden

\section{Correspondence to} Professor Niels Lynøe, CHE, Karolinska Institutet, 171 77, Stockholm, Sweden; niels.lynoe@ki.se

Received 20 March 2012 Revised 16 July 2012 Accepted 31 July 2012 Published Online First 30 July 2013

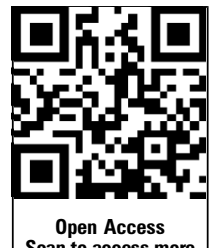

\section{SLinked}

- http://dx.doi.org/10.1136/ medethics-2012-100998

- http://dx.doi.org/10.1136/ medethics-2012-101000

- http://dx.doi.org/10.1136/

medethics-2013-101724

To cite: Lynøe N, Leijonhufvud M. J Med Ethics 2013:39:772-775.

\title{
Police in an intensive care unit: what can happen?
}

\author{
Niels Lynøe, ${ }^{1}$ Madeleine Leijonhufvud ${ }^{2}$
}

\begin{abstract}
During spring 2009 a Swedish senior paediatric intensivist and associate professor was detained and later prosecuted for mercy-killing a child with severe brain damage. The intensivist was accused of having used high doses of thiopental after having withdrawn life-sustaining treatment when the child was imminently dying. After more than 2.5 years of investigation the physician was acquitted by the Stockholm City Court. The court additionally stated that the physician had provided good end-of-life care. Since the trial it has become evident that the accusation was based on a problematic medicolegal report. Nevertheless, the event has had severe negative consequences for the physician personally and professionally, and probably also, in general, for patients in the final stage of life. This case illustrates, together with other cases, that there is a lack of correspondence between ethical soft law/healthcare law and the Penal Code. To optimise medical practice we suggest that the criminal law be carefully examined and if possible changed. Furthermore, we suggest a peer-review system for assessing medicolegal reports in cases of suspected homicide.
\end{abstract}

\section{BACKGROUND}

The story began when a premature newborn baby who had gone through a complicated breech birth was accidently mistreated with an infusion containing too high a concentration of sodium chloride, which might have resulted in comprehensive brain damage-see box 1. The patient was dependent on ventilator treatment. After an MR examination corroborating the pessimistic prognosis, physicians recommended and the parents accepted that the life-sustaining treatment should be withdrawn. Since the parents were deeply concerned about the course of events during the previously provided care, a senior paediatric intensivist was called in to take charge of the end-of-life treatment. As palliation the child received an intravenous morphine infusion only and died about $5 \mathrm{~h}$ after the ventilator treatment had been discontinued. Previously the child had had convulsions, and accordingly thiopental infusion was prepared in case the child had distressing seizures while dying. But the child was quite calm and thiopental was not needed and therefore not given.

The parents were content with the end-of-life treatment but felt that they had not been properly informed about the severe brain damage. They went to the police. Although the hospital had begun an investigation (via the National Board of Health and Welfare) into the initial mistreatment, the police requested a forensic examination. The examination, conducted more than 3 weeks after the child died, included quantification of morphine and thiopental concentrations from a blood sample. These findings verified the severe brain damage but also indicated a very high blood concentration of thiopental. The medicolegal expert stated that it was thiopental had caused the patient's death and concluded that, since it is not possible to live with such a concentration of thiopental, it must have been given in huge doses during the very last phase of the patient's life. According to the medicolegal expert there were no other reasonable explanations. This reasoning was the basis for the decision to prosecute the intensivist for manslaughter. The motive was understood as mercy killing.

\section{QUESTIONS ARISING DURING THE PROCESS}

The blood concentration of thiopental 24 days post mortem was questioned by the defence, and the prosecutor requested a second opinion from the National Board of Health and Welfare's forensic council. A Norwegian medicolegal expert was asked to re-examine the case and deliver an opinion as to whether or not the conclusion drawn by the Swedish medicolegal expert was correct. The Norwegian expert answered that the conclusion could be correct, but-and this was a big but-several other hypotheses might explain the findings. Furthermore, he considered the role of thiopental to be minimal.

During the trial it became evident that at least one (other) physician had treated the child with thiopental shortly before the life-sustaining treatment was withdrawn. Probably, several physicians had treated the patient with thiopental in order to inhibit convulsions, for intubation before a surgical procedure and medical examinations. Thiopental is usually provided until a therapeutic effect is obtained. This is a normal procedure and since the patient was still receiving ventilator treatment, the medication was obviously not lethal. Unfortunately-and contrary to regulations-the thiopental administrations were not entered in the medical record.

Nobody questioned that thiopental was found in the blood sample, but since no control sample had been collected and the available one was very small, it was difficult to quantify the concentration. Little is known about the passage of thiopental over the blood-brain barrier in brain-damaged premature infants. ${ }^{1}$ Furthermore, it is difficult to calculate the dose administered from the concentration of thiopental in a 24-day post mortem blood sample. The interpretation of post mortem concentrations is difficult and the post mortem redistribution of drugs has been described as a toxicological nightmare. ${ }^{2}$

\section{WHY DID COLLEAGUES REMAIN SILENT?}

One question which needs to be asked is why the physician(s) who had previously given thiopental 


\section{Box 1 Facts about the premature newborn baby}

- Born in week 25 weight: $850 \mathrm{~g}$.

- It was a difficult breech birth with an Apgar score of 1+1+1 and resuscitation was started (15 min).

- Day 2, an excessively high sodium chloride concentration and severe brain damage was identified.

- The sodium chloride was mistakenly provided by a nurse. It was not possible to conclude whether the brain damage was caused by the high sodium chloride concentrations or the difficult breech birth.

- Neonatologists suggested that intensive care be reduced, but the parents objected.

- After 3 months the child suddenly became worse, and an MR examination demonstrated the comprehensiveness of brain damage. The parents accepted the decision to withdraw the life-sustaining treatment.

- The child died about $5 \mathrm{~h}$ after the ventilator treatment was discontinued.

- When the child died it was 3 months and 17 days old and weighed $3500 \mathrm{~g}$.

- The body was placed in a mortuary for 24 days before an autopsy was conducted. During this period the body was removed temporarily for a memorial service held by the family.

- When examining the brain, the medicolegal expert found nothing but a liquid. A blood sample (containing $3 \mathrm{ml}$ liquid) was taken from a femoral artery. No control sample was collected-for example, from the cavities of the heart.

did not enter the fact in the medical record. There might be several reasons. First, it is understandable that under a heavy workload on an intensive care unit entering data in the medical record is not given highest priority. Furthermore, the physicians concerned were asked about it almost half a year after the event and stated that they did not remember.

It seems reasonable for physicians not to remember a specific case in which they provide thiopental. Even so, they might be expected to admit that they might have used thiopental in the contexts described. But all the physicians concerned remained silent. One reason might be that they were afraid of being sanctioned for not having recorded the treatment. Another explanation might be that if the physicians had actually given high doses of thiopental in order to obtain symptom relief, they might have feared that they, like the intensivist, would be accused of misconduct or something worse. It is not hard to imagine physicians fearing the prospect of being prohibited from working for more than $2 \frac{1}{2}$ years and being accused of having committed a crime when they had been offering everything possible in order to help both the relatives and the patient through the last hours of life. If you want avoid the risk of being suspected of, accused, or prosecuted for, killing someone to whom you have provided good relief, you will probably be very careful when alleviating the patients' symptoms. You might prefer to be too careful and accordingly, rather be accused of neglect than manslaughter.

\section{HEALTHCARE LAW AND THE PENAL CODE}

In Swedish healthcare it is generally considered good clinical practice to provide drugs to alleviate patients' suffering in the last phase of life, even if the treatment might shorten life. If the intention of using a drug is to alleviate suffering and not to shorten life it is generally acceptable to provide such drugs even
Box 2 Healthcare laws, soft laws and the Penal Code in Sweden

It is solely when a patient dies unexpectedly, or if a crime can be suspected, that physicians have an obligation to contact the police or a coroner. When a patient's death is expected as a result of a life-threatening disease or after a decision to withdraw life-sustaining treatment, the police or coroners are usually not contacted.

If a healthcare provider is suspected of having mistakenly caused the death of a patient, the case is supposed to be reported to the National Board of Health and Welfare by the head of the clinic concerned. After examination, the Board can make decisions on its own authority in order to prevent similar future events. The board may also refer the case to a disciplinary board (HSAN), which may take actions and criticise the individual healthcare provider and, for example, require him/ her in the future to comply with healthcare law. If a crime is suspected, the Board will turn the case over to the prosecutor and/or police. Relatives can always go to the police. Depending on how the prosecutor considers the case he/she might decide to prosecute a healthcare provider.

In Sweden, as in all rule of law countries, shortening a fellow human being's life is considered a crime. Just as in other countries, the Penal Code defines exceptions-for example, in certain cases of self-defence and emergency. In the Code, however, no specific exception is made for healthcare providers acting in emergencies-for example, when a patient in terminal care is given alleviating treatment which also shortens life. Under healthcare law, a healthcare provider has an obligation to alleviate such a patient's symptoms and omission to do so is considered to be neglect.

though the patient's life is shortened. ${ }^{3}$ This was recently stated by the Swedish Board of Health and Welfare in another related case-see box 2. The Swedish Board of Health and Welfare is supposed to help healthcare professionals to interpret healthcare law and to this end formulates so-called 'soft law'. ${ }^{4}$ But under the Swedish Penal Code shortening a fellow human being's life ranks as murder or manslaughter, depending on the circumstances. Since it is difficult to look inside the head of a physician and observe his/her intentions when providing drugs that might both alleviate symptoms and shorten life, a court will have to consider the foreseen effect and the circumstances when assessing whether or not an act is to be considered criminal. According to the healthcare law it is considered neglectful for a physician to abstain from providing adequate symptom alleviation when urgently needed, while on the other hand providing too much might in such cases, according to the prosecutor in this case, be considered manslaughter.

Let us assume that the physician in this case had given high doses of thiopental in order to treat convulsions after withdrawing the ventilator treatment. Let us also assume that it was an emergency (no time for titrating thiopental), then such a treatment would have shortened life and resulted in high postmortem concentrations of thiopental. Should such a procedure be classified as a criminal offence even if it is in accordance with good clinical practice? In order to prevent that prosecutors are becoming interested in different end-of-life-care treatments, and physicians seem to have created different strategies: they use timers on a ventilator in order to transform an act of withdrawal 
to a withholding one. ${ }^{5}$ We think that the lack of correspondence between healthcare law/soft law and the Penal Code has tacitly led to suboptimal clinical practice.

As is the case in many other national legal systems, the Swedish Penal Code contains provisions exempting certain acts-for example, in self-defence and in emergencies, from being classed as criminal. Emergencies occur when two different values or interests compete. It could, and has been, argued that a greater value, controlling a dying patient's unbearable symptoms, over-rides and justifies the value of preserving the patient's life a little longer. In such situations a physician who helps a patient by controlling his/her symptoms thus usually escapes being accusations of manslaughter. This non-liability principle has evolved in case law but has not been introduced into the Penal Code. It usually works as long as the treatment provided is considered compatible with good clinical practice. The problem in this case is that in our view prosecutors in Sweden have little experience of what constitutes good clinical practice. This view is supported by the recent decision of the prosecutor general to select 12 prosecutors with special responsibility for healthcare issues. We believe that the case we cover in this paper was part of the impetus for this decision. ${ }^{7}$ Similar reasoning could be applied when dealing with sedation and withdrawal of life-sustaining treatment-see box 3 .

The codification of the non-liability principle in the Penal Code, referring to current good clinical practice, would mean that a prosecutor, before deciding whether or not to prosecute a healthcare provider, would have to consult the National Board of Health and Welfare. The Board is usually the authority which defines the current state of art, and accordingly considers whether or not a treatment is in accordance with good clinical practice. In this case the Board examined the medical treatment of the patient after withdrawal of the life-sustaining treatment. It found that the treatment provided was fully in accordance with good clinical practice. ${ }^{8}$ Accordingly, if we add such a provision to the Swedish Penal Code we might avoid unnecessary prosecutions and thus improve medical practice and patient safety. We state this as a suggestion which, accordingly, should be examined carefully with respect to patient safety.

\section{WHAT CAN BE LEARNT FROM THIS CASE?}

In the aftermath of the case the Swedish Medical Journal published an interview with the accused physician. ${ }^{9}$ This interview was quoted in several newspapers and read by the attorney general, the chief public prosecutor and the head of the national police board. Each of these authorities has decided to investigate what went wrong in this particular case. Recently, the chief public prosecutor concluded that the prosecutor in the present case managed it correctly. ${ }^{10}$ Accordingly, it was not a mistake to prosecute the intensivist. In future more patients and relatives may be inclined to go to the police when they feel that something has gone wrong within the healthcare system. However, to improve medical practice and patient safety and to prevent unnecessary police invasions of intensive care units and unnecessary prosecutions, we believe two steps must be taken.

The Swedish medicolegal expert's conclusion seems to be too focused on one single hypothetical explanation, even though there were others. In Sweden there is no supervision or control of the medicolegal expert's judgements and conclusions. We suggest that a peer review system within forensic medicine be introduced for cases of suspected homicide. Such a system could prevent a prosecutor placing too much weight on a single medicolegal expert's opinion.

\section{Box 3 Related cases preceding the present case}

During the past 6 years we have had three additional cases illustrating discrepancies between the Penal Code and healthcare ethics, soft law and healthcare laws. The first case (2006) concerned a competent patient who was dependent on ventilator treatment and who asked to be sedated and the treatment discontinued. The patient (32 years old) was completely paralysed after a car accident. The physician refused. He had consulted the National Board of Health and Welfare whose chief legal adviser was of the opinion that such an act would constitute manslaughter or murder. The patient went to Switzerland for an assisted suicide. In the subsequent discussion it became clear that it had been unnecessary for the patient to undertake such a long and difficult journey. Several legal experts found that the Penal Code was contradicted by both the Swedish Constitution and by healthcare law. Refusing to help the patient in a case like this was considered to be coercive treatment, which is prohibited and criminal. The discussion led to a change of standpoint by the National Board of Health and Welfare. The change became evident during 2010 when a competent and totally paralysed patient sent a letter to the National Board of Health and Welfare asking permission to be sedated and for ventilator treatment to be discontinued. The Board answered that in the situation described this wish should be granted. An intensivist at the hospital was prepared to help the patient. But $1 \mathrm{~h}$ before the sedation and disconnection was planned to take place, the intensivist was advised (by the hospital's chief legal adviser) not to discontinue the ventilator treatment, since one could not exclude the possibility of subsequent prosecution.

Both the above-mentioned patients might have lived for several years and discontinuing the ventilator treatment meant that their lifespan was significantly shortened.

A third issue discussed in Sweden is the legal situation with respect to sedation (terminal sedation) at the end of life. The treatment implies that the patient is sedated and that no fluid or nutrition is provided, resulting in death after a couple of days or a week. Such a patient's life might be shorted more or less significantly, depending on when sedation is started. It is unknown if applying sedation several weeks before an expected death would be against the Penal Code. Palliative care physicians are cautious about providing sedation and usually apply it only when the patient is in the very final phase (the last 1 or 2 days).

Unfortunately, this is not an isolated case. In Sweden, during the past 6 years we have had three cases illustrating discrepancies between the Penal Code and healthcare ethics, soft law and healthcare laws-see box 3 . So if society wants to ensure that patients can be provided with adequate palliation at the end of life, it will also have to provide a minimum of 'physician safety'. But this should be done without jeopardising patient safety. One way to improve the legislative system would, in our opinion, be to add a provision to the 'exceptions' already stated in the Penal Code, from penal liability in cases of self defence, emergency, consent, etc. This provision should state that an act or an omission within the healthcare system is not a crime if it accords with good clinical practice. Changing the Penal Code is a serious matter and should be conducted carefully, considering all possible patient safety aspects. But if 'physician safety' is a precondition for patient safety the Penal Code should be changed. 
Contributors Both authors contributed equally to the manuscript. NL contributed to the medical aspects and ML to the legal aspects.

\section{Competing interests None.}

Provenance and peer review Not commissioned; externally peer reviewed.

Open Access This is an Open Access article distributed in accordance with the Creative Commons Attribution Non Commercial (CC BY-NC 3.0) license, which permits others to distribute, remix, adapt, build upon this work non-commercially, and license their derivative works on different terms, provided the original work is properly cited and the use is non-commercial. See: http://creativecommons.org/ licenses/by-nc/3.0/

\section{REFERENCES}

1 Norman E, Malmqvist U, Westrin $\mathrm{P}$, et al. Thiopental pharmacokinetics in newborn infants: a case report of overdose. Acta Paediatrica 2009;98:1680-2.

2 Ferner R. Post-mortem clinica pharmacology. Br J Clin Pharmacol 2008;66(4):430-43.
3 Inwald D, Vandyck W. Ethical debate: the distinction between withdrawing life sustaining treatment under the influence of paralysing agents and euthanasia. Paralysing agents may be given up to but not at or beyond the point of extubation. BMJ 2001;323(7309):389-90.

4 Socialstyrelsen. The National Board of Health and Welfare's regulations and general advice about life-sustaining treatment. http://www.socialstyrelsen.se/sosfs/2011-7 (accessed 5 Apr 2013).

5 Ravitsky V. Timers on ventilators. BMJ 2005;330:415-17.

6 Lynøe N, Juth N. Does proficiency creativity solve legal dilemmas? Experimental study of medical students' ideas about death-causes. Med Health Care Philos. Published Online First: 20 Dec 2012. doi:10.1007/s11019-012-9460-2

7 Gunnarsdotter $S$. The prosecutor general initiate special healthcare prosecutors. Swed Med J (Läkartidningen) 2013;110(7):330.

8 Gunnarsdotter S. The National Board of Health and Welfare found no misconduct in the Astrid Lindgren case. Swed Med J (Läkartidningen) 2009;106:2701.

9 Gunnarsdotter S. Acquitted-after two years, eight month and nine days. Swed Med J (Läkartidningen) 2011;108(51):2694-703.

10 Gunnarsdotter $S$. No critique of the prosecutor (In the Astrid Lindgren case). Swed Med J (Läkartidningen) 2012;109(19):942. 